\title{
A EXPLORAÇÃO DAS MÁXIMAS CONVERSACIONAIS E O TÓPICO DISCURSIVO EM COMENTÁRIOS DO PERFIL
}

\author{
@LAERTEGENIAL DO INSTAGRAM
}

\author{
Maria da Penha Pereira Lins ${ }^{1}$ \\ Jucélia Azevedo dos Santos Silva²
}

\begin{abstract}
Resumo: Com o advento das novas tecnologias digitais, surgiram também muitas mídias sociais, nas quais seus participantes estão sempre em interação. Com isso, o processo comunicativo acontece de forma diferente do que estávamos habituados, visto que as produções textuais em rede são construídas de forma dinâmica, multimodal e imediata. Esse contexto digital exige dos estudiosos da linguagem um novo olhar sobre o texto, pois a perspectiva de análise textual agora é diferente da até então adotada pela Linguística Textual, em que o texto se apresentava em ordem linear. No espaço virtual, as informações do texto podem se apresentar em ordens variadas. Assim, há também vários modos de interação. Pensando nesse processo interacional e nessa nova perspectiva de texto, este artigo propõe uma interface entre Linguística Textual e Pragmática, buscando um diálogo entre a teoria das implicaturas e a noção de topicalidade. Para tanto, analisamos comentários do perfil do Instagram @laertegenial e observamos de que forma as implicaturas aconteceram e como isso afetou o tópico discursivo da interação. Notamos que muitas dessas violações resultaram em ampliação ou desvio do tópico, entretanto isso não comprometeu, necessariamente, a coerência textual. Este trabalho está embasado na Teoria das Implicaturas de Grice (1982); e na noção de topicalidade segundo Fávero (2010), Jubran (2015), Lins (2008) e Koch (1999).
\end{abstract}

Palavras-chave: Pragmática. Implicatura. Tópico discursivo. Instagram.

Abstract: With the advent of new digital technologies, many social media have also emerged in which their participants are always in interaction. Thereby, the communicative process happens differently than we were used to, whereas textual productions on the internet are built in a dynamic, multimodal and immediate way. This digital context requires language scholars to take a new look at the text, since the perspective of textual analysis is currently different from that previously adopted by Text Linguistics, in which the text was presented in a linear order. In the virtual space, text information can be presented in varied orders. Thus, there are also several modes of interaction. Thinking about this interactional process and this new perspective of text, this article proposes an interface between Text Linguistics and Pragmatics,

\footnotetext{
${ }^{1}$ Professora do Programa de Pós-graduação em Estudos Linguísticos da Universidade Federal do Espírito Santo (UFES), Vitória-ES. Brasil. E-mail: mpenhalins@gmail.com

${ }^{2}$ Mestranda em Estudos Linguísticos pela Universidade Federal do Espírito Santo (UFES) e professora de Língua Portuguesa do Instituto Federal do Espírito Santo (IFES), Vitória-ES. Brasil. E-mail: jucelia.azevedo@ifes.edu.br
} 
aiming for a dialogue between the theory of implicature and the concepts of discourse topic. Therefore, comments were analyzed from the Instagram profile @laertegenial and then observed on how the implicature occurred and how they had affected the discourse topic of the interaction. We attested that many of these violations resulted in extension or deviation from the topic, however this did not necessarily compromise textual coherence. This work is based on Grice's Theory of Implicature (1982); and in the notions of discourse topic according to Fávero (2010), Jubran (2015), Lins (2008) and Koch (1999).

Keywords: Pragmatics. Implicature. Discourse topic. Instagram.

\section{Considerações iniciais}

Conforme Levinson (2007), uma das preocupações da pragmática é estudar a relação entre a língua e seu contexto, ou seja, ela se preocupa com o significado linguístico em situação real de uso. Com o advento das novas tecnologias digitais, surgiram também muitas mídias digitais, nas quais seus participantes estão sempre em interação, e o processo comunicativo acontece de outras formas, visto que as produções textuais na web são construídas de forma não linear, multimodal e imediata. Além disso, os textos inseridos nesse ambiente são produzidos cooperativamente, uma vez que o espaço promove o poligerenciamento textual entre seus usuários.

Esse contexto digital exige dos estudiosos da linguagem um novo olhar sobre o texto, porque além da interatividade entre seus usuários, há outras características na prática textual da Web 2.0 que merecem atenção, a saber, a multimodalidade, a fluidez, a dinamicidade, o poligerenciamento. Uma perspectiva de análise de texto diferente da até então adotada pela Linguística Textual - doravante LT, em que o texto se apresentava em uma ordem mais linear.

Com essa preocupação, buscaremos neste trabalho observar comentários na rede social Instagram referentes a uma postagem motivadora publicada no perfil @laertegenial. Com isso, pretendemos promover um diálogo entre a Pragmática e a Linguística Textual. Para tanto, focaremos as implicaturas conversacionais e o tópico discursivo, bem como suas funções pragmático-discursivas. E para isso, serão tomados como matizes teóricos os postulados de Grice ([1975]1982), no que diz respeito à teoria das implicaturas; Fávero (2010), Jubran (2015), Lins (2008) e Koch (1999) no tocante ao tópico discursivo.

Tendo em vista que há uma conexão constante entre os textos produzidos no ambiente do Instagram e que as significações dos textos surgem a partir do processo 
interacional, observaremos de que forma as máximas conversacionais griceneanas são violadas, nos comentários dos usuários, e como as implicaturas surgidas a partir dessas violações contribuíram para o desvio/ a manutenção do tópico discursivo.

\section{A Pragmática}

Uma das principais teorias da pragmática é a das implicaturas cujo principal nome é o do filósofo Paul Grice ([1975]1982) que contribuiu muito para os estudos pragmáticos, sobretudo no que diz respeito ao Princípio da Cooperação e suas Máximas Conversacionais, na medida em que propôs um modelo capaz de explicar o processo conversacional. Nesse modelo, o significado literal aparece apenas como parte do que está sendo comunicado, isto é, veiculamos em um ato comunicativo o significado semântico (o dito) e o significado pragmático (o implicado) ao mesmo tempo.

Segundo Grice ([1975]1982), no processo conversacional, os enunciados não podem ser entendidos como "frases" desconectadas, pois há, em nossas interações, um contrato intuitivo que rege nossa conversação, na qual os participantes fazem esforços cooperativos o tempo todo. Se você convidar uma amiga para um café da tarde, por exemplo, criar-se-á uma expectativa de resposta positiva ou negativa para o convite. Não se espera que a convidade dê uma resposta totalmente sem nexo. Isso acontece porque fazemos esforços para compreender o outro e para sermos compreendidos pelo outro, ou seja, o diálogo é uma atividade cooperativa. É esse contrato tácito que permite o sucesso da conversa. Pensando nisso, Grice ([1975]1982) formulou o princípio da cooperação para a conversação:

\footnotetext{
Podemos formular, então, um princípio muito geral que se esperaria que os participantes observassem: Faça sua contribuição conversacional tal como é requerida, no momento em que ocorre, pelo propósito ou direção do intercâmbio conversacional em que está engajado. (GRICE, 1982, p. 86).
}

Este princípio geral é constituído pelas máximas conversacionais, as quais foram organizadas por ele em quatro categorias: máxima da quantidade (forneça informações suficientes); máxima da qualidade (fale a verdade); máxima da relação (seja relevante); e máxima do modo (seja claro). 
Conversamos de forma eficiente quando observamos o que cada máxima especifica, mesmo que inconscientemente. No entanto, vale ressaltar que nem sempre essas máximas são obedecidas à risca. Isso porque muitas vezes as abandonamos de forma proposital, a fim de sinalizar para nosso interlocutor que ele precisa ampliar aquele significado literal da informação. Quando isso ocorre, emerge uma dimensão pragmática do significado- a informação não dita, mas comunicada pelo falante.

Esse tipo de inferência é o que Grice ([1975]1982) chamou de implicatura conversacional, uma informação que vai além do que está dito explicitamente, ou seja, perpassa o sentido literal do enunciado. "As implicaturas são disparadas quando o falante abandona explicitamente o princípio [...] e assim quer que seu intérprete perceba que está sendo cooperativo em outro nível” (OLIVEIRA, BASSO, p.34, 2014). Nesse sentido, o falante espera que seu interlocutor infira outro conteúdo que está para além do significado semântico da sentença. Essas informações não ditas, mas comunicadas, sinalizam as intenções do falante.

Vale ressaltar que as implicaturas conversacionais estão atreladas ao contexto de produção dos enunciados. Desse modo, um mesmo enunciado pode disparar implicaturas diferentes a depender do contexto. O enunciado "que bonito!", por exemplo, pode significar um elogio em uma determinada situação; contudo, também pode indicar uma desaprovação, em tom de ironia, em outra.

\section{A noção de tópico discursivo}

Pode-se dizer de forma mais abrangente que o tópico pode ser compreendido como "sobre o que está falando", desse modo, conforme Jubran (2015) a estruturação tópica serve como fio condutor da organização textual-interativa. Para Fávero (2010, p. 45), "ele é antes de tudo uma questão de conteúdo, estando na dependência de um processo colaborativo que envolve os participantes do ato interacional" (grifo da autora). Assim, na constituição de um texto falado, o tópico discursivo é um elemento essencial, já que ele decorre do processo colaborativo.

O tópico envolve interesse e conhecimento partilhados entre os indivíduos envolvidos no processo interacional, desse modo, conforme Fávero (2010) é uma atividade construída de forma cooperativa, ou seja, há uma correspondência de 
objetivos entre os interlocutores, ainda que parcialmente. É nessa interação que as significações são construídas.

Ainda segundo Fávero (2010), um tópico pode ocorrer de forma implícita advindo do conhecimento partilhado, por isso nem sempre a identificação do tópico é clara. Mesmo que, aparentemente, o tópico não seja facilmente identificado, o contexto ajuda a estabelecer a coerência do texto, já que os interlocutores, a partir de seus conhecimentos partilhados, sabem de qual tópico estão tratando no momento da interação.

Jubran (2015) caracteriza como sendo duas as propriedades definidoras do tópico. A primeira, que norteia o tópico, é a de centração, a qual abrange três traços: a) concernência: relação de interdependência entre elementos do texto; b) relevância: proeminência de elementos textuais projetados como focais; e c) pontualização: tida como um foco dado em determinado momento do texto falado. Para Fávero (2010, p. 47), “Centração é o falar-se acerca de alguma coisa, implicando a utilização de referentes explícitos ou inferíveis" (grifo da autora). Dessa forma, quando surge uma nova centração - conteúdo-, tem-se também um novo tópico.

Já a segunda propriedade, a de organicidade, decorre das relações de interdependência tópica que se instaura concomitantemente nos planos hierárquico e linear. O primeiro engloba as dependências de superordenação e subordenação entre os tópicos que se implicam pelo grau de abrangência do assunto; o segundo refere-se às articulações entre os tópicos em termos de adjacência ou interposições de tópicos diferentes na linha do texto.

A noção de hierarquia, que diz respeito às relações de interdependência intertópicas, permite perceber níveis na estruturação dos tópicos, que vão de porções maiores a fragmentos mínimos. Nessa estrutura enxerga-se um quadro tópico que compõe um supertópico (ST) - um tópico mais abrangente, que pode ser dividido internamente em subtópico (Sbt), que por sua vez pode ser subdividido em pequenos fragmentos - segmentos tópicos.

No que diz respeito ao plano linear, é possível compreender dois fenômenos básicos que compõem a organicidade: a continuidade e a descontinuidade. A continuidade decorre da organização sequencial dos tópicos, ou seja, a abertura de um novo tópico só acontece após o fechamento do tópico anterior. Lins (2008, p. 33) esclarece dizendo que "a progressão/continuidade tópica diz respeito ao conjunto de 
segmentos tópicos que, direta ou indiretamente, são relacionados com o tema geral”. A descontinuidade, por sua vez, decorre de uma perturbação na sequencialidade, isto é, antes do tópico anterior ser esgotado, um novo tópico é introduzido na linha discursiva. O tópico precedente pode ou não ser retomado na linha discursiva. Quando isso não acontece, tem-se a ruptura; quando há o retorno, têm-se as inserções e as digressões.

\begin{abstract}
As inserções desempenham funções interativas relevantes, como explicar, ilustrar, atenuar, fazer ressalvas, introduzir avaliações ou atitudes do locutor etc., e podem ser realizadas por vontade do próprio locutor, ou podem ser também, hetero-condicionadas, quando o interlocutor assalta o turno e faz uma pergunta e/ou pede um esclarecimento, o que leva o locutor a ser obrigado a interromper sua elocução e a responder ao interlocutor. (LINS, 2008, p. 27)
\end{abstract}

Já “a digressão pode ser definida como uma porção de conversa que não se acha diretamente relacionada com o tópico em andamento." (FÁVERO, 2010, p. 59). Embora ela seja normalmente introduzida sem marca formal, pode surgir com operadores que indicam que a digressão feita de forma intencional, como por exemplo: a propósito, por falar nisso etc.

É importante pontuar que embora a digressão e a inserção aparente uma não relação direta com o tópico precedente e com o seguinte, isso não implica em incoerência textual, já que em uma conversação, pela própria característica da dinamicidade, os tópicos apresentam constantes flutuações. Aliás, "as inserções e as digressões não só não prejudica a coerência, mas, pelo contrário, muitas vezes ajudam a construí-la" (LINS, 2008, p. 27).

\title{
Análise
}

A fim de compreender como se dá a organização interativa nos comentários do Instagram, pensamos em abordar conhecimentos teóricos acerca da topicalidade com o intuito de descobrir sua função nessa organização. Para tanto, a análise se deu a partir de uma postagem motivadora (abaixo), publicada no perfil @laertegenial em 31 de maio de 2019. Na data do acesso (20/06/19), havia mais de seiscentos comentários referentes a esta postagem. 

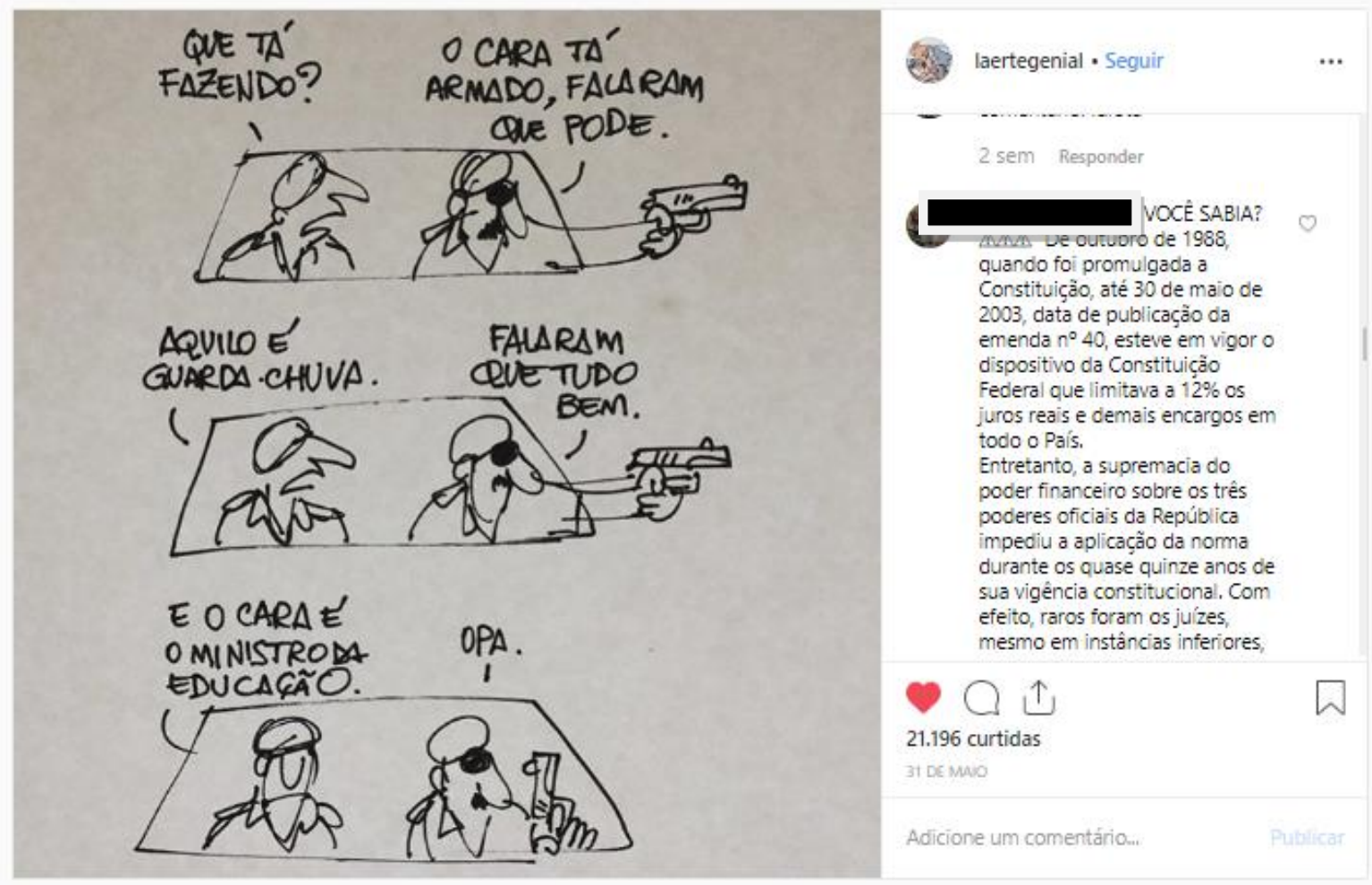

Fonte: LAERTE (2019).

Esta charge, de autoria da cartunista brasileira Laerte Coutinho, foi publicada um dia depois de o ex-ministro da educação Abraham Weintraub divulgar um vídeo no qual, munido de um guarda-chuva e de forma satírica, fala a respeito da verba destinada à recuperação do Museu Nacional. Isso causou muita repercussão nas mídias digitais.

A charge sugere a ideia de um policial que ameaça atirar em um suposto "cara" por imaginar que ele está armado. Ao perceber que o tal homem era o ministro da educação, o policial recua da decisão imediatamente. Com isso, é possível observar que esta arte evidencia as ideias defendidas pelo presidente do Brasil, Jair Bolsonaro, e o ex-ministro da justiça, Sérgio Moro. Além de fazer referência a Weintraub e seu episódio do guarda-chuva.

Ao publicar esta charge, Laerte comunica outras informações que não estão colocadas de forma explícita. Desse modo, seus interlocutores precisam fazer esforços cooperativos para inferir o que a cartunista deseja significar. Dessa charge, podem emergir várias implicaturas e, a depender do conhecimento de mundo dos seguidores 
do perfil @laertegenial, no Instagram, elas podem ser capturadas ou não. Isso pode desencadear outras implicaturas diferentes nos comentários da postagem.

Nessa interação processamos ao mesmo tempo a informação dada e a implicada, sendo assim, é possível inferir que, de forma irônica, Laerte faz uma crítica ao atual governo e a sua equipe, criticando, sobretudo, o pacote de segurança - proposto por Moro; o despreparo da polícia e a atuação negativa do ex-ministro da educação.

Nessa negociação de sentidos, Laerte está sendo cooperativa na medida em que compreende o propósito do intercâmbio conversacional e fornece informações explícitas e implícitas para significar. Mas para que a comunicação tenha êxito é preciso que o interlocutor também seja cooperativo, pois os participantes da conversação precisam fazer esforços cooperativos para que isso ocorra.

A publicação desta charge no perfil do Instagram @laertegenial resultou em vários comentários, positivos e também negativos. A partir da leitura dos comentários, notamos a presença de um tópico central segurança pública, no entanto apareceram também outros tópicos como armas, política, Laerte, comentários, ministro da justiça, ministro da educação. Como as produções dos comentários acontecem de forma dinâmica, observamos, no desenrolar da interação, que a conversação entre os usuários vai se modificando e, consequentemente, o tópico discursivo vai sendo alterado.

\section{Comentário 1 (usuário 1)}

Figura 2 - Comentário 1.

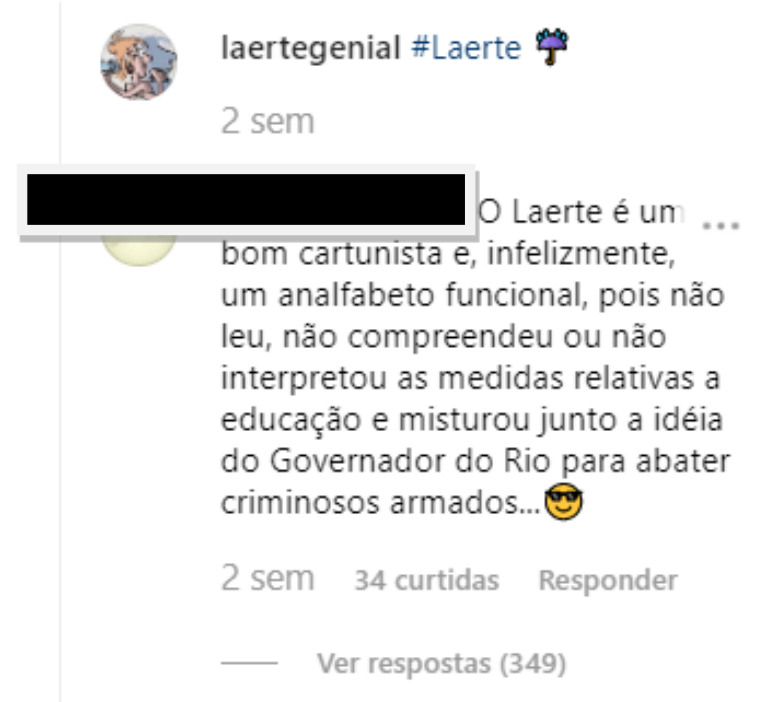


Fonte: LAERTE GENIAL, Instagram, 2019.

O Laerte é um bom cartunista e, infelizmente, um analfabeto funcional, pois não leu, não compreendeu ou não interpretou as medidas relativas a educação $e$ misturou junto a ideia do Governador do Rio para abater criminosos armados...

Observamos que o comentário 1 foi feito baseado no que o autor do comentário inferiu da charge. E, mesmo a chargista sendo cooperativa, uma vez que fornecem pistas que nos orienta para o significado semântico e pragmático, ele restringiu muito o significado da charge. Como consequência disso, o usuário responde à postagem com uma postura agressiva, ofendendo Laerte.

Além do mais, ele não apresenta evidência suficiente para aquilo que está afirmando sobre Laerte e, portanto, viola a máxima da qualidade estabelecida por Grice ([1975]1982), que trata justamente da veracidade da informação. Não há como ele afirmar que a cartunista não leu ou não compreendeu tais medidas. Ademais, é possível inferir que a charge não trata diretamente da ideia de abate de criminosos armados defendida pelo ex-governador do Rio de Janeiro, Wilson Witzel, mas sim se refere a um dos pontos mais polêmicos do pacote anticrime proposto pelo ex-ministro Sérgio Moro: a excludente de ilicitude.

Este comentário dispara outras implicaturas, entre elas a de que o autor do comentário aprova, de certa forma, as medidas propostas pelo ex-ministro da educação, como o contingenciamento no orçamento da educação, por exemplo. No entanto, a ofensa à cartunista foi o gatilho para exacerbar a discussão.

Com isso, o comentário obteve mais de trezentas interações, o que resultou em uma interação paralela à da postagem motivadora. Muitos usuários continuaram a interagir com a postagem da charge, outros, porém, passaram a interagir também com o autor do comentário 1. Focamos, para nossa análise, a interação entre o autor da postagem acima (usuário 1) e um segundo usuário (usuário 2), que respondeu ao comentário em questão. Optamos por este recorte pelo fato de a conversação entre os dois ter se prolongado a ponto de acompanharmos do início ao término da interação 
PERcursos Linguísticos • Vitória (ES) •v. 10 •n. 26 • 2020 • ISSN: 2236-2592 •

Dossiê: Linguagem, Comunicação e Cognição •

entre eles. Isso permitiu observar quando o tópico era mantido, modificado ou abandonado. Selecionamos alguns desses comentários para demonstrar como isso ocorreu.

\section{Comentário 2 (usuário 2)}

Figura 3- Comentário 2

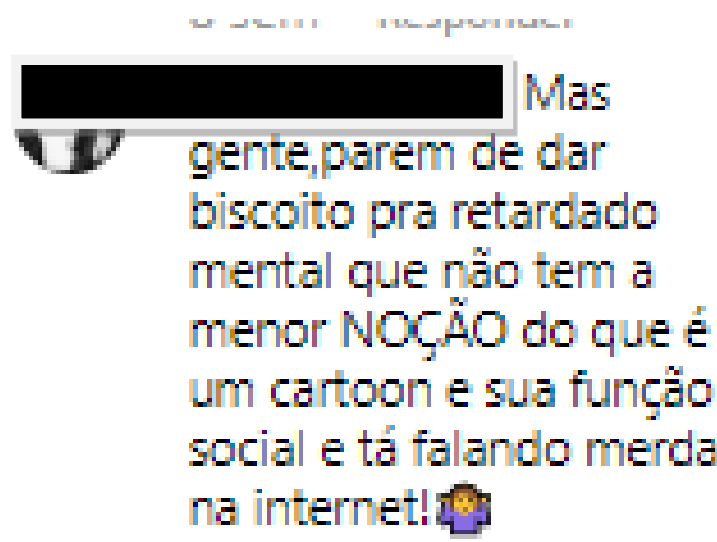

8 sem 10 curtidas

Responder

Fonte: LAERTE GENIAL, Instagram, 2019.

Mas gente,parem de dar biscoito pra retardado mental que não tem a menor NOÇÃO do que é um cartoon e sua função social e tá falando merda na internet!

No comentário acima, o usuário 2 ofende o usuário1. Ele também aparenta violar a máxima da qualidade quando acusa o seu interlocutor de não ter conhecimento acerca do gênero cartum (o usuário fez referência à charge como sendo o gênero cartum). Vale ressaltar que, mesmo aparentemente violando a máxima, o Princípio da Cooperação ainda está sendo mantido, visto que o usuário 2 faz isso estrategicamente para causar algum efeito no seu interlocutor. Neste caso, para inflamar a discussão ("Mas gente, parem de dar biscoito pra retardado mental”), provocar ("não tem a menor NOÇÃO do que é um cartoon") e até ofender o usuário 1 ("retardado mental", “tá falando merda na internet!”). 
PERcursos Linguísticos • Vitória (ES) •v. 10 •n. 26 • 2020 • ISSN: 2236-2592 •

Dossiê: Linguagem, Comunicação e Cognição •

Uma nova implicatura surge neste comentário. Não está dito explicitamente, porém é possível inferir que este segundo usuário tem um apreço pela cartunista, bem como concorda com o que foi colocado por ela na charge. Nota-se também um tom de indignação com o comentário do usuário 1, já que Laerte é vítima de insultos. Em resposta àquele comentário, o usuário 2 também usa um tom agressivo na tentativa de desqualificá-lo. Com isso, o fio condutor da conversa, cujo tópico central era a cartunista Laerte, vai sendo modificado, ou seja, agora o foco está sendo dado ao gênero textual cartum.

\section{Comentário 3 (usuário 2)}

Figura 4 - Comentário 3

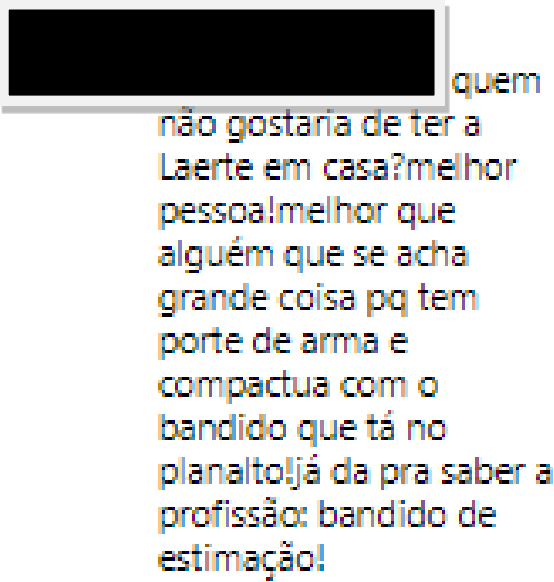

8 sem 9 curtidas

Responder

quem não gostaria de ter a Laerte em casa?melhor pessoa!melhor que alguém que se acha grande coisa pq tem porte de arma e compactua com o bandido que tá no planalto! já da pra saber a profissão: bandido de estimação!

Este comentário é uma resposta a outro comentário do usuário 1, que, em um dado momento do diálogo, sugere para o usuário 2- que defende a cartunista durante as interações- levar Laerte para casa. 
PERcursos Linguísticos • Vitória (ES) •v. 10 •n. 26 • 2020 • ISSN: 2236-2592 •

Dossiê: Linguagem, Comunicação e Cognição •

Aqui o tópico cartum é interrompido, e reintroduzido outro tópico cuja centração está novamente na cartunista, quando é mencionado na mensagem que todo mundo gostaria de ter a presença de Laerte em casa. No entanto, ocorre um desvio natural do tópico que evolui para um novo assunto: o caráter e a profissão do seu interlocutor.

Quando o usuário 2 menciona a profissão, no lugar de trazer uma informação pertinente ao contexto, como professor, contador, cantor, usa a expressão "bandido de estimação". Além de ofendê-lo, implica também o posicionamento político/ideológico tanto seu quanto do seu interlocutor, quando faz menção ao palácio do planalto e ofende implicitamente o presidente da república ("compactua com o bandido que tá no planalto!'). Percebe-se, contudo, que essas implicaturas são intencionais e com propósitos bem definidos: revidar, criticar, desafiar, ofender o usuário 1.

\section{Comentário 4 (usuário 2)}

Figura 5 - Comentário 4

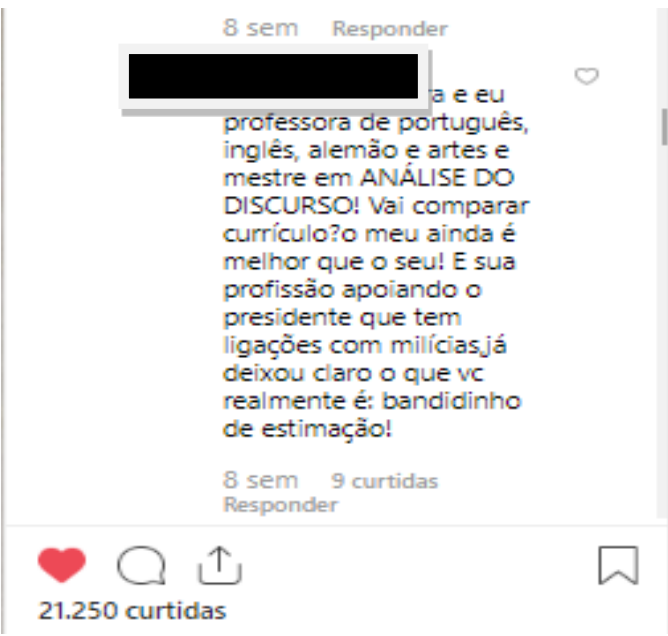

Fonte: LAERTE GENIAL, Instagram, 2019.

e eu professora de português, inglês, alemão e artes e mestre em ANÁLISE DO DISCURSO! Vai comparar currículo?o meu ainda é melhor que o seu! E sua profissão apoiando o presidente que tem ligações com milícias,já deixou claro o que vc realmente é: bandidinho de estimação! 
Em réplica ao comentário três, o usuário um informa ao seu interlocutor que é professor de administração e história, e também militar. O usuário dois reage em tom de desafio, quando destaca que é “mestre em ANÁLISE DO DISCURSO” e quando instiga seu interlocutor a comparar os currículos. Ao enfatizar que é mestre em Análise do Discurso, a usuário dois implica que tem propriedade para analisar o que foi colocado por seu interlocutor. Mais uma vez, a máxima da qualidade é violada propositalmente, quando sem apresentar evidências suficientes, o usuário dois provoca ("Vai comparar currículo?o meu ainda é melhor que o seu!"), ("E sua profissão apoiando o presidente que tem ligações com milícias") e ofende seu interlocutor (“bandidinho de estimação!”).

\section{Considerações finais}

A partir do exposto, foi possível verificar que no processo interacional do Instagram, assim com como na interação face a face, os textos não são organizados aleatoriamente. Existe uma noção discursiva de tópico que é inferida pelos participantes da interação e que gerencia a conversação. Esse tópico pode ser alterado ou abandonado conforme intervenção dos interlocutores, que podem em um dado momento focar em um assunto, que vai dando lugar a outros. Como pode ser visto na análise do corpus, isso ocorre porque "a mudança na definição da situação no interior de uma interação é um processo emergente e dinâmico" (KOCK, 1999, p. 82), seja em uma conversação prototípica, seja em interações em plataformas digitais.

Isso demonstra que não há como prever com exatidão qual rumo pode tomar um diálogo, visto que a dinamicidade e a rapidez na construção textual possibilitam interações paralelas que podem resultar em manutenção, alteração ou descontinuidade tópica, de modo que "[...] ao final de uma conversação, os parceiros, em geral, estão bem distantes do tópico original" (KOCK, 1999, p. 87-88).

Nos comentários analisados, observamos que da charge inicial, que tinha como tópico central a segurança pública, resultou uma multiplicidade de tópicos, como cartum, Laerte, profissão, currículo, e muitos outros que não puderam ser contemplados neste trabalho. Mas, apesar disso, os esforços cooperativos entre os participantes garantiram que a conversação fosse conduzida de forma coerente. 
PERcursos Linguísticos • Vitória (ES) •v. 10 •n. 26 • 2020 • ISSN: 2236-2592 •

Dossiê: Linguagem, Comunicação e Cognição •

Nas nossas análises, percebemos que a discussão iniciou quando o usuário um ofendeu Laerte Coutinho, ao chamá-la de analfabeta funcional, o que desencadeou uma série de ofensas entre os usuários um e dois. Com isso, observamos que, da violação das máximas nos comentários, emergiram diferentes implicaturas, que tiveram uma função estratégica nas interações, muitas vezes com o intuito de contra argumentar o interlocutor ou até mesmo para inflamar a discussão.

É importante salientar que não foi possível contemplar todos os comentários da postagem, dada à complexidade desse tipo de análise. Dessa forma, as eventuais lacunas serão preenchidas em investigações futuras.

\section{Referências}

FÁVERO, L. L. O tópico discursivo. In: PRETI, Dino (Org.). Análise de textos orais. São Paulo: Humanitas, 2010.

GRICE, H. P. Lógica e conversação. In: DASCAL, M. (org.) Fundamentos metodológicos da Linguística. Pragmática. V. 4. Campinas, 1982, p. 81-103.

JUBRAN, C. S. Tópico discursivo. In: JUBRAN, C. S. (Org.). Gramática do português culto falado no Brasil: Volume 1 - A construção do texto falado. São Paulo: Contexto, 2015.

KOCK, I. G. V. Digressão e relevância conversacional. In: Cadernos de Estudos Linguísticos. Campinas. No 37. Jul-dez. 1999. PP. 81-91.

LEVINSON, S. C. Pragmática. Tradução: Luís Carlos Borges e Aníbal Mari. São Paulo: Martins Fontes, 2007.

LINS, M. P. P. O tópico discursivo em textos de quadrinhos. Vitória: Edufes, 2008.

OLIVEIRA, R. P.; BASSO, R. M. Arquitetura da conversação: teoria das implicaturas. 1. ed. São Paulo: Parábola, 2014. 